\title{
Noncategorical identification of rise time
}

\author{
JACEK SMURZYŃSKI \\ Warsaw Academy of Music, Laboratory of Music Acoustics, Warsaw, Poland
}

\begin{abstract}
The view that speech and certain nonspeech signals such as music are perceived categorically has been contradicted by many studies. In most studies, subjects identified many different stimuli as belonging to one of two classes (e.g., "pluck" and "bow"). To determine whether subjects can identify exactly each of a number of different stimuli, subjects heard a sawtooth wave contained within six different amplitude envelopes. In one task, subjects learned the envelopes by rise-time value $(10,20,30,40,50$, and $60 \mathrm{msec})$, and later identified them by pressing labeled keys. Analysis of responses showed that accuracy of estimating envelope rise time is not worse than $\pm 10 \mathrm{msec}$. It is concluded that subjects trained in auditory perception do not classify a continuum of sawtooth waveforms varying in rise time into two sharply defined categories, but are able to resolve rise-time values with much greater accuracy than is achieved by simply dividing the $10-60$-msec range into two categories such as "pluck" and "bow."
\end{abstract}

Within the last 4 years there has been a new interest in categorical-like perception of nonspeech signals. In 1981 Rosen and Howell determined that categorical discrimination functions could not be obtained for music-like stimuli spaced with equal intervals of the rise time, as had been reported by Cutting and Rosner (1974). Hary and Massaro (1982) argued that categorical perception was questionable for both speech and nonspeech continua. Results of a study conducted by Kewley-Port and Pisoni (1984) appeared to follow Weber's law, which is the opposite of categorical perception.

In most experiments, subjects have been asked to identify each stimulus as either "pluck" or "bow." This task directs subjects to classify stimuli into two groups, although eight or more signals may be used in an experiment. To elucidate a further point of interest, an experiment was designed to determine whether it was possible for subjects to identify exactly each stimulus as it was presented.

\section{METHOD}

\begin{abstract}
Stimuli
Amplitude envelopes of six stimuli were generated digitally on an Olivetti M-20 microcomputer and stored in memory. The amplitude envelope of each stimulus rose linearly from 0 to its maximum in $10,20,30,40,50$, and $60 \mathrm{msec}$. The steady-state portion was followed by a 40-msec linear decay. The overall length of the stimuli was $250 \mathrm{msec}$. Thus the length of the steady state covaried with the duration of the onset ramps from 150 to $200 \mathrm{msec}$.

The amplitude envelopes were output under computer control at a 5-kHz sampling rate through a 10-bit multiplying $\mathrm{D} / \mathrm{A}$ converter and multiplied by a 300-Hz sawtooth wave (Hewlett Packard 3312 function generator). The stimuli were then amplified and presented binaurally through TDH-39 headphones at $70 \mathrm{~dB}$ above threshold
\end{abstract}

The research reported here was supported by the Polish Academy of Sciences, Program MR.I.24. The author's mailing address is: Warsaw Academy of Music, Laboratory of Music Acoustics, 2 Okolnik, 00-368, Warsaw, Poland. in a quiet testing room. Each stimulus started at a positive-going zero crossing.

\section{Procedure}

The procedure was divided into two parts: learning and identification testing. The first task introduced subjects to the 10-, 20-, 30-, 40-, 50-, and 60-msec rise-time stimuli. The subject used the remote control to call each of six amplitude envelopes stored in the computer memory. Each stimulus lasting $250 \mathrm{msec}$ was played back, at the rate of $1 / \mathrm{sec}$. A subject could call each of the six stimuli as many times as needed to fix them in his or her memory. There were no restrictions on the number or order of the calls by the subjects. Following initial training, the identification task was run. On each trial, the subject heard one of the six stimuli repeated several times with a 1-sec silent interval between successive tones. The subject had to identify which of the six basic signals was presented by pressing one of six buttons labeled with the values $10,20,30$, 40,50 , and $60 \mathrm{msec}$. There was no time limit; an answer terminated a trial. There was an extra 5-sec interval between trials.

In a block of 30 trials, each of the six stimuli was presented five times in a random order constrained so that the difference of the rise time in successive trials was at least $20 \mathrm{msec}$. A similar criterion was used by Cutting (1982) and Rosen and Howell (1981) with a two-step ABX procedure. Eight sessions of 30 trials each gave 40 identifications per stimulus per subject.

\section{Subjects}

Six subjects, 5 males and 1 female, all graduate students at the Sound Engineering Department of the Warsaw Academy of Music, participated in the experiment. All subjects were aware of the purpose of the test and were paid for their participation. All of them had passed a special course on the so-called timbre solfeggio. The main goal of this course is to develop timbre perception skills, that is, to increase timbre sensitivity and improve timbre memory (Letowski, 1985). One part of the timbre solfeggio program deals with the discrimination and memorization of typical rise and decay times of various stimuli.

\section{RESULTS}

Figure 1 presents the data accumulated over all subjects. The rise-time values are plotted along the horizontal axis and the corresponding percent of labeling is plotted vertically. The distribution of labeling is shown 
separately for each stimulus. Since, according to Cutting and Rosner (1974), category boundaries for the two classes of stimuli are between 30 and $40 \mathrm{msec}$ for pulses of sawtooth waves, an analysis of identifications for the 30 - and the $40-\mathrm{msec}$ stimuli seemed to be of particular interest. The $30-\mathrm{msec}$ stimulus was identified by the subjects as having a rise time of $20 \mathrm{msec}$ in $16.3 \%$ and $40 \mathrm{msec}$ in $19.2 \%$ of the responses. That means the stimulus that should have been labeled as "pluck" was identified equally often as belonging to the "pluck" or "bow" categories. Similar data were obtained for the $40-\mathrm{msec}$ stimulus. It was judged as the $30-\mathrm{msec}$ pulse in $23.3 \%$ and as the 40 -msec pulse in $21.3 \%$.

No suggestion was given to the subjects about the criteria they should use in making their judgments. They were not familiar with the idea of categorical perception of plucks and bows. After the experiment most of the subjects reported that stimuli with different rise times differed in timbre quality, and that they used a timbre criterion to memorize the stimuli. The ability of subjects to identify and describe the basic properties of sound seems to have an influence on the results of experiments testing categorical perception (see, e.g., Rosen \& Howell, 1981). The data of the present experiment were obtained for subjects highly experienced in timbre differentiation. Evidently, within the whole group of stimuli the subjects did not find any rapid change of timbre sensation that would facilitate judgment and make it less likely for them to identify stimuli with the rise time of $30 \mathrm{msec}$ as $40-\mathrm{msec}$ pulses, or vice versa.

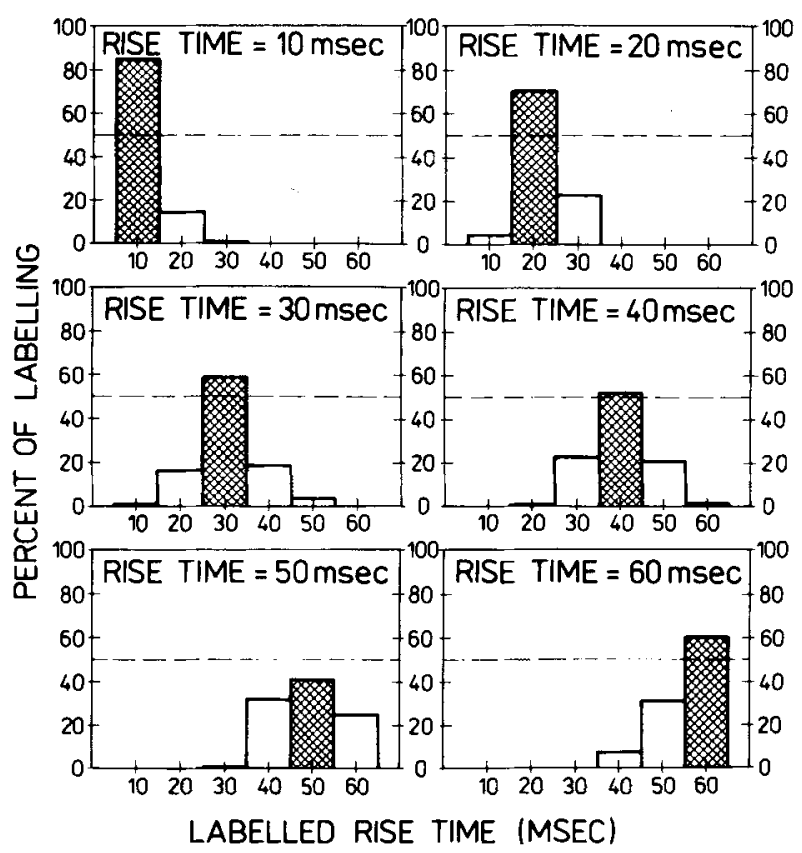

Figure 1. Percent of labeling versus labeled rise time for the stimuli with rise times of $10,20,30,40,50$, and 60 msec. The values of correct identification are marked off.
Table 1

Percent of Correct Identification with Accuracy $\pm 10 \mathrm{msec}$

\begin{tabular}{ccc}
\hline $\begin{array}{c}\text { Nominal Value } \\
\text { of Rise Time }\end{array}$ & $\begin{array}{c}\text { Labeled } \\
\text { Rise Time }\end{array}$ & $\begin{array}{c}\text { Percent of } \\
\text { Responses }\end{array}$ \\
\hline 10 & 10 or 20 & 99.2 \\
20 & 10 or 20 or 30 & 100 \\
30 & 20 or 30 or 40 & 94.3 \\
40 & 30 or 40 or 50 & 96.7 \\
50 & 40 or 50 or 60 & 98.7 \\
60 & 50 or 60 & 92.1 \\
\hline
\end{tabular}

Table 1 shows the data obtained by adding percent correct to identification rate for adjacent values to the nominal rise time. As can be seen, the subjects could absolutely identify the rise time with an accuracy not worse than $\pm 10 \mathrm{msec}$ (more than $90 \%$ of responses for all conditions). This is, of course, a preliminary estimation. Undoubtedly, much better accuracy could be obtained by changing the rise-time continuum and experimental procedure.

One of the criteria of categorical perception states that subjects are able to discriminate only sounds that are identified as belonging to different categories. According to Kewley-Port and Pisoni (1984), the Weber fraction calculated as $\Delta$ RT/RT (rise time) for the sawtooth stimuli was 0.8 for $R T=10 \mathrm{msec}, 0.4$ for $R T=20 \mathrm{msec}$, and around 0.2 for rise times in the $30-60 \mathrm{msec}$ range. This means that 10-msec step increases of the rise time should be discriminated. Kewley-Port and Pisoni obtained these results for subjects who were unfamiliar with psychoacoustic experiments. Undoubtedly, trained listeners could detect smaller differences. This has been confirmed by an experiment of the author's which is in progress now. There is no doubt about the ability to discriminate signals differing by $10 \mathrm{msec}$ in their rise times (for rise times shorter than $60 \mathrm{msec}$ ). This is in agreement with the data reported by van Heuven and van den Broecke (1979) for sine waves.

\section{CONCLUSIONS}

Six subjects trained in auditory perception did not classify a continuum of sawtooth wave forms varying in rise time into two sharply defined categories. Their accuracy in identifying the rise-time values was much better than that based on dividing a $10-60-\mathrm{msec}$ range into the categories "plucks" and "bows." These subjects' accuracy of estimation of the rise time was not worse than $\pm 10 \mathrm{msec}$.

\section{REFERENCES}

Cutring, J. E. (1982). Plucks and bows are categorically perceived sometimes. Perception \& Psychophysics, 31, 462-476.

Cutting, J. E., \& Rosner, B. S. (1974). Categories and boundaries in speech and music. Perception \& Psychophysics, 16, 561-570.

HarY, J. M., Massaro, D. W. (1982). Categorical results do not imply categorical perception. Perception \& Psychophysics, 32, 409-418. 
Kewley-Port, D., \& Pisoni, D. B. (1984). Identification and discrimination of rise time: Is it categorical or noncategorical? Journal of the Acoustical Society of America, 75, 1168-1176.

LȨTOWSKI, T. (1985). Development of technical listening skills: Timbre solfeggio. Journal of the Audio Engineering Society, 33, 240-244.
Rosen, S. M., \& Howell, P. (1981). Plucks and bows are not categorically perceived. Perception \& Psychophysics, 30, 156-168

van Heuven, V. J. J. P., \& van den Broecke, M. P. R. (1979), Auditory discrimination of rise and decay times in tone and noise bursts. Journal of the Acoustical Society of America, 66, 1308-1315.

(Manuscript received October 16, 1985;

accepted for publication November 4,1985 .) 